\title{
Comprehensive Experimental and Theoretical Study of the CO + NO Reaction Catalyzed by Au/Ni Nanoparticles
}

\author{
Georgios Kyriakou, ${ }^{\dagger, \uparrow}$ Antonio M. Márquez, ${ }^{\S}$ Juan Pedro Holgado," Martin J. Taylor, ${ }^{\dagger, \nabla}{ }_{\odot}$
} Andrew E. H. Wheatley, ${ }^{\perp} \odot$ Joshua P. Mehta, ${ }^{\perp}$ Javier Fernández Sanz, ${ }^{\S} \odot$ Simon K. Beaumont, ${ }^{*},{ }^{\bullet}$ and Richard M. Lambert ${ }^{*},{ }_{\odot}$

${ }^{\dagger}$ European Bioenergy Research Institute, Aston University, Aston Triangle, Birmingham B4 7ET, United Kingdom

${ }^{\ddagger}$ Department of Chemical Engineering, Department of Chemical Engineering, University of Patras, GR-26500 Patras, Greece

${ }^{\S}$ Departamento de Química Física, Facultad de Química, Universidad de Sevilla, E-41012 Sevilla, Spain

"Instituto de Ciencia de Materiales de Sevilla (CSIC-University of Seville) and Departamento de Quimica Inorganica, University of Seville, Avda. Americo Vespucio, 49, 41092 Seville, Spain

${ }^{\perp}$ Department of Chemistry, Cambridge University, Cambridge CB2 1EW, United Kingdom

\#Department of Chemistry, University of Durham, Durham DH1 3LE, United Kingdom

Supporting Information

ABSTRACT: The catalytic and structural properties of five different nanoparticle catalysts with varying $\mathrm{Au} / \mathrm{Ni}$ composition were studied by six different methods, including in situ X-ray absorption spectroscopy and density functional theory (DFT) calculations. The as-prepared materials contained substantial amounts of residual capping agent arising from the commonly used synthetic procedure. Thorough removal of this material by oxidation was essential for the acquisition of valid catalytic data. All catalysts were highly selective toward $\mathrm{N}_{2}$ formation, with 50-50 Au:Ni material being best of all. In situ X-ray absorption near edge structure spectroscopy showed that

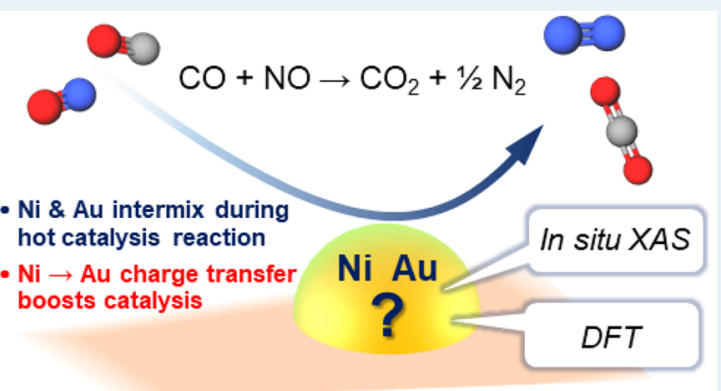
although $\mathrm{Au}$ acted to moderate the oxidation state of $\mathrm{Ni}$, there was no clear correlation between catalytic activity and nickel oxidation state. However, in situ extended X-ray absorption fine structure spectroscopy showed a good correlation between $\mathrm{Au}-\mathrm{Ni}$ coordination number (highest for $\mathrm{Ni}_{50} \mathrm{Au}_{50}$ ) and catalytic activity. Importantly, these measurements also demonstrated substantial and reversible $\mathrm{Au} / \mathrm{Ni}$ intermixing as a function of temperature between $550{ }^{\circ} \mathrm{C}$ (reaction temperature) and $150{ }^{\circ} \mathrm{C}$, underlining the importance of in situ methods to the correct interpretation of reaction data. DFT calculations on smooth, stepped, monometallic and bimetallic surfaces showed that $\mathrm{N}+\mathrm{N}$ recombination rather than NO dissociation was always rate-determining and that the activation barrier to recombination reaction decreased with increased $\mathrm{Au}$ content, thus accounting for the experimental observations. Across the entire composition range, the oxidation state of $\mathrm{Ni}$ did not correlate with activity, in disagreement with earlier work, and theory showed that $\mathrm{NiO}$ itself should be catalytically inert. $\mathrm{Au}-\mathrm{Ni}$ interactions were of paramount importance in promoting $\mathrm{N}+\mathrm{N}$ recombination, the rate-limiting step.

KEYWORDS: Bimetallic catalysts, in situ measurements, DFT, active species, effect of Au, reaction mechanism

\section{INTRODUCTION}

The $\mathrm{CO}+\mathrm{NO}$ reaction was studied on extended single crystal surfaces for the first time over 40 years ago $^{1}$ and many investigations have been published in the succeeding decades. The reaction continues to attract attention, ${ }^{2}$ reflecting its key role in the abatement of automotive emissions. In addition to its technical importance, the metal-catalyzed $\mathrm{CO}+\mathrm{NO}$ reaction is an attractive subject for both experimental and theoretical study ${ }^{3,4}$ thanks to its apparent relative simplicity. In the case of well-defined extended single crystal surfaces, experimental results can be comparatively simple to interpret. However, with practical catalysts consisting of metal nanoparticles dispersed on metal oxide supports, additional complexities arise and comprehensive reviews devoted to the use of monometallic catalysts are available. ${ }^{5,6}$ Bimetallic systems introduce important additional flexibility into catalyst design and optimization and have therefore been extensively investigated for a wide variety of organic, ${ }^{7}$ petrochemical, ${ }^{8}$ and electrochemical ${ }^{9}$ reactions, as well as the $\mathrm{CO}+\mathrm{NO}$ reaction. ${ }^{10}$

With regard to the $\mathrm{CO}+\mathrm{NO}$ reaction, the use of goldnickel nanoparticle catalysts was recently patented by Toyota, on the basis of work conducted in both Cambridge, UK and

Received: December 28, 2018

Revised: April 10, 2019

Published: April 19, 2019 
Table 1. Composition and Size Information for Unsupported Nanoparticles (Top) and Supported Nanoparticle Samples (Bottom)

\begin{tabular}{|c|c|c|c|c|c|c|}
\hline \multicolumn{7}{|c|}{ unsupported nanoparticles } \\
\hline $\begin{array}{l}\text { catalyst and nominal } \\
\text { metal ratio/\% }\end{array}$ & $\begin{array}{l}\text { Au:Ni I } \\
\text { unsuppor }\end{array}$ & $\begin{array}{l}\mathrm{CP} \text { molar ratio of } \\
\text { rted nanoparticles }\end{array}$ & \multicolumn{2}{|c|}{$\begin{array}{l}\text { relative } \mathrm{Au} / \mathrm{Ni} \text { ratio of EDS signals of } \\
\text { unsupported nanoparticles }\end{array}$} & \multicolumn{2}{|c|}{$\begin{array}{l}\text { TEM particle size (diameter) and distribution } \\
\text { before deposition } / \mathrm{nm}^{c}\end{array}$} \\
\hline $\mathrm{Au}_{100}$ & & & & \multicolumn{2}{|l|}{$3.1( \pm 1.2)$} \\
\hline $\mathrm{Au}_{75} \mathrm{Ni}_{25}$ & & $75: 26$ & \multicolumn{2}{|c|}{$15( \pm 9)$} & \multicolumn{2}{|l|}{$3.7( \pm 1.2)$} \\
\hline $\mathrm{Au}_{50} \mathrm{Ni}_{50}$ & & $50: 51$ & \multicolumn{2}{|c|}{$8.1( \pm 4.5)$} & \multicolumn{2}{|l|}{$2.4( \pm 1.3)$} \\
\hline $\mathrm{Au}_{25} \mathrm{Ni}_{75}$ & & $25: 74$ & \multirow{2}{*}{\multicolumn{2}{|c|}{$2.7( \pm 2.7)$}} & \multicolumn{2}{|l|}{$3.1( \pm 1.0)$} \\
\hline $\mathrm{Ni}_{100}$ & & & & & $3.7( \pm 0.6)$ & \\
\hline \multicolumn{7}{|c|}{ supported samples } \\
\hline $\begin{array}{l}\text { catalyst and } \\
\text { nominal metal } \\
\text { ratio } / \%\end{array}$ & $\begin{array}{l}\mathrm{Au}: \mathrm{Ni} \text { ICP molar } \\
\text { ratio of } \\
\text { supported } \\
\text { nanoparticles }^{a}\end{array}$ & $\begin{array}{l}\text { total metal } \\
\text { loading }\end{array}$ & $\begin{array}{l}\text { TEM particle size } \\
\text { (diameter) and } \\
\text { distribution of supported } \\
\text { nanoparticles } / \mathrm{nm}^{c}\end{array}$ & $\begin{array}{l}\text { TEM particle size } \\
\text { (diameter) and } \\
\text { distribution after } \\
\text { calcination } / \mathrm{nm}^{c}\end{array}$ & $\begin{array}{l}\text { TEM particle size } \\
\text { (diameter) and } \\
\text { distribution after reduction } \\
\text { and catalysis } / \mathrm{nm}^{c}\end{array}$ & $\begin{array}{c}\text { PXRD-derived } \\
\text { particle diameter } \\
\text { after catalysis/ } \\
\mathrm{nm}^{e}\end{array}$ \\
\hline $\mathrm{Au}_{100} / \alpha-\mathrm{Al}_{2} \mathrm{O}_{3}$ & & $\begin{array}{l}0.1 \mathrm{mmol} \cdot \mathrm{g}^{-1} \\
5.3 \text { wt } \%\end{array}$ & $3.4( \pm 1.3)$ & $70( \pm 25)$ & $17( \pm 10)$ & 11 \\
\hline $\mathrm{Au}_{75} \mathrm{Ni}_{25} / \alpha-\mathrm{Al}_{2} \mathrm{O}_{3}$ & $75: 19$ & $\begin{array}{l}0.2 \mathrm{mmol} \cdot \mathrm{g}^{-1}, 4.2 \\
\text { wt } \%\end{array}$ & $4.9( \pm 2.5)$ & $11.3( \pm 4.6)$ & $11.7( \pm 5.5)$ & 7 \\
\hline $\mathrm{Au}_{50} \mathrm{Ni}_{50} / \alpha-\mathrm{Al}_{2} \mathrm{O}_{3}$ & $50: 45$ & $\begin{array}{l}0.14 \mathrm{mmol} \cdot \mathrm{g}^{-1} \\
1.9 \text { wt } \%\end{array}$ & $5.0( \pm 3.2)$ & $13.3( \pm 5.4)$ & $24( \pm 7)$ & 15 \\
\hline $\mathrm{Au}_{25} \mathrm{Ni}_{75} / \alpha-\mathrm{Al}_{2} \mathrm{O}_{3}$ & $25: 84$ & $\begin{array}{l}0.25 \mathrm{mmol} \cdot \mathrm{g}^{-1} \\
1.8 \text { wt } \%\end{array}$ & $5.6( \pm 2.6)$ & $9.3( \pm 2.9)$ & $11.0( \pm 3.4)$ & 8 \\
\hline $\mathrm{Ni}_{100} / \alpha-\mathrm{Al}_{2} \mathrm{O}_{3}$ & & $\begin{array}{l}0.27 \mathrm{mmol} \cdot \mathrm{g}^{-1} \\
5.3 \text { wt } \%\end{array}$ & $-f$ & $5.5( \pm 1.6)$ & $9.0( \pm 2.5)$ & $-^{e}$ \\
\hline
\end{tabular}

${ }^{a}$ Presented with respect to $\mathrm{Au}$ amount expected for ease of comparison. ${ }^{b}$ Uncalibrated values as a guide to relative composition only; values obtained are a ratio of $\mathrm{Au} \mathrm{M} / \mathrm{Ni} \mathrm{L}$ edges obtained from individual particles (see exemplar images in the Supporting Information) and the distribution given is one standard deviation. ${ }^{c}$ Distribution indicated based on one standard deviation of particle size count. ${ }^{d}$ Target loading $\sim 0.2$ $\mathrm{mmol} \mathrm{\textrm {g } ^ { - 1 }}$. ${ }^{e}$ Obtained by Scherrer analysis from the Au (311) reflection, hence Ni only sample not shown. ${ }^{f_{\text {Too }}}$ small/oxidic to measure against alumina support.

Japan. ${ }^{11}$ Beniya et al. used a $\mathrm{Au} / \mathrm{Ni}(111)$ single crystal model system to examine the effects of surface composition on the reaction, concluding that the beneficial effect of $\mathrm{Au}$ incorporation was due to a reduction in the activation energy for the reaction $\mathrm{N}(\mathrm{a})+\mathrm{N}(\mathrm{a}) \rightarrow \mathrm{N}_{2}(\mathrm{~g})$, thought to be the overall rate limiting step. ${ }^{12}$ Their subsequent in situ study of a single catalyst consisting of $\sim 1: 1 \mathrm{Au}-\mathrm{Ni}$ bimetallic particles supported on silica confirmed the effect of Au addition, but left open a number of key questions, including the actual condition of catalyst before and after reaction, the nature of the $\mathrm{Au}-\mathrm{Ni}$ interaction, its dependence on composition, and the identity of the catalytically active sites. ${ }^{13}$ As the authors themselves concluded "However, the nature of the active sites remains very complicated, and there is room for further investigation." The object of the present paper is to identify or clarify the key issues.

Here we report the results of a comprehensive experimental and theoretical investigation of the $\mathrm{CO}+\mathrm{NO}$ reaction catalyzed by $\mathrm{Au} / \mathrm{Ni}$ nanoparticles of varying composition. Experimentally, particular attention was given to the method of sample preparation and, especially, the oxidative pretreatment applied to remove extensive polymeric residues, whose presence can radically affect the nature of the working catalyst. It was found that the methods previously used for such catalysts (e.g., $300{ }^{\circ} \mathrm{C}$ in air) ${ }^{13}$ are inadequate. Although the catalysts underwent some sintering as a result of calcination in air, they retained their bimetallic nature and were stable against further sintering during subsequent reduction and catalytic reaction. Thorough pretreatment is an important point that is frequently overlooked or unreported in studies of metal catalysts prepared by colloidal routes, whose conclusions should therefore be regarded with circumspection. X-ray absorption spectroscopy (XAS) results obtained under in situ reaction conditions provided key information about the structure and electronic state of the working catalysts. Specifically, these observations elucidated the nature, frequency and impact on $\mathrm{Ni}$ oxidation state of the $\mathrm{Au}-\mathrm{Ni}$ interaction and showed that the extent of this interaction correlated well with catalytic activity. Importantly, they also showed that substantial and reversible changes in $\mathrm{Au}-\mathrm{Ni}$ intermixing occurred as a function of temperature, essential information for a correct interpretation of catalytic data. This is in contrast to ex situ powder X-ray diffraction (PXRD) and Xray photoelectron spectroscopy (XPS) methods, which obviously cannot provide structural information pertinent to reaction conditions. Density functional theory (DFT) calculations on both smooth and stepped surfaces showed that, relative to pure $\mathrm{Ni}$, the activation barrier to $\mathrm{N}+\mathrm{N}$ recombination was progressively lowered by increasing amounts of $\mathrm{Au}$ up to $~ 50 \%$, in good accord with experiment. This lowering in the activation barrier was overwhelmingly due to the destabilization of adsorbed $\mathrm{N}$ atoms, which bind much more strongly to pure nickel than to bimetallic sites. Moreover, this process, rather than NO dissociation, was overall rate determining. DFT calculations also showed that $\mathrm{NiO}$ should be catalytically inert in the $\mathrm{CO}+\mathrm{NO}$ reaction. The importance of $\mathrm{Au}-\mathrm{Ni}$ intermixing at elevated temperatures $\left(\sim 550{ }^{\circ} \mathrm{C}\right)$ in catalyzing the $\mathrm{CO}+\mathrm{NO}$ reaction, identified here, has not been reported for other reactions catalyzed by combinations of gold and nickel, such as low temperature $\mathrm{CO}$ oxidation $\left(<100^{\circ} \mathrm{C}\right)$, where a Au-NiO core-shell structure is proposed, ${ }^{14}$ or methane steam reforming, where Au blocks step sites that are susceptible to coking. ${ }^{15}$ 


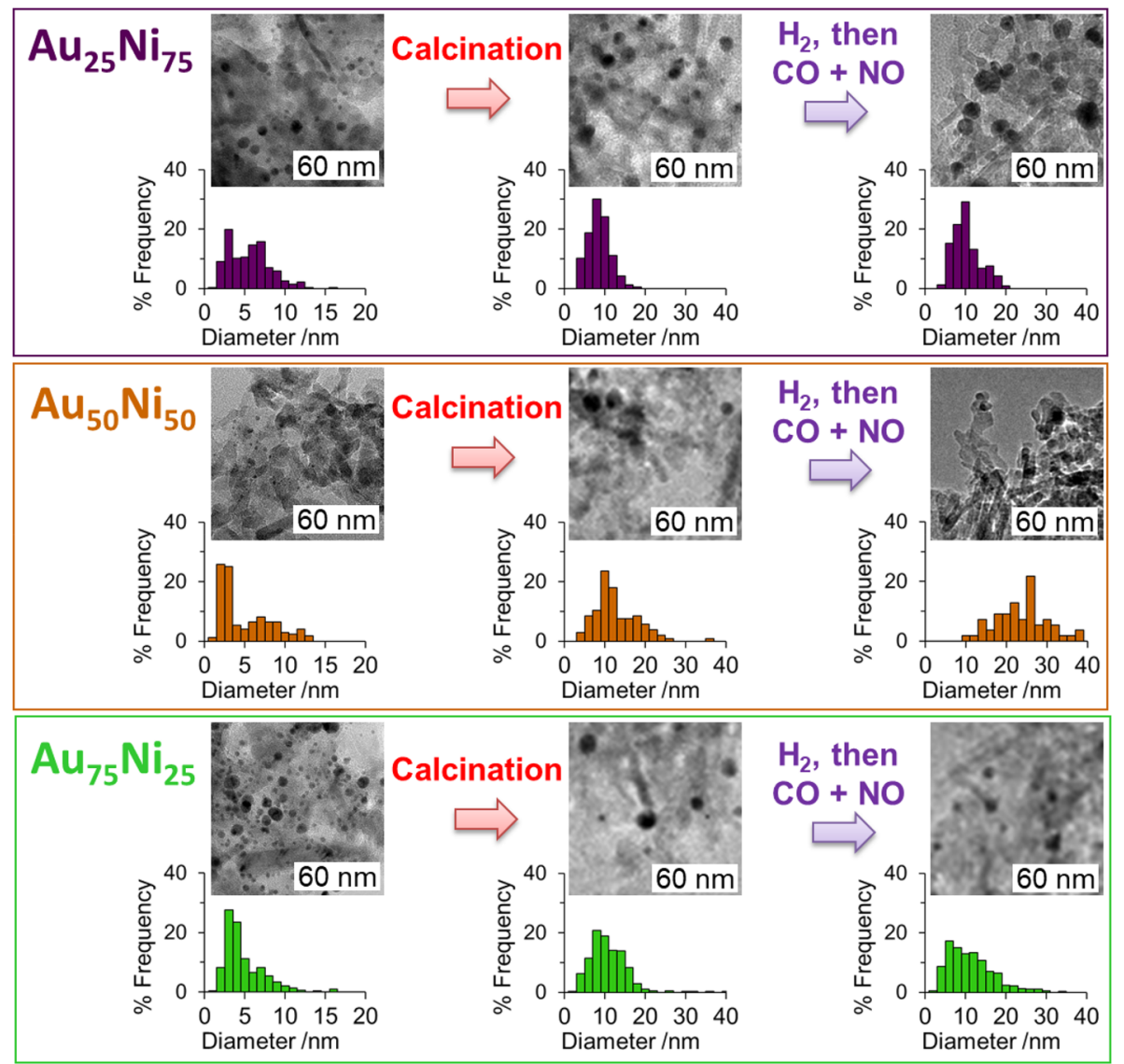

Figure 1. Representative TEM images of supported bimetallic nanoparticle-based samples before calcination (left column), after calcination and before reduction (central column), and after in situ reduction and catalytic reaction (right column).

\section{EXPERIMENTAL METHODS}

Catalysts were prepared on $\alpha$-alumina from colloidal nanoparticles, purified by thorough washing, and by post deposition calcination to remove residual synthetic agents. A range of ex situ characterization (transmission electron microscopy [TEM], energy dispersive spectroscopy [EDS], XPS, inductively coupled plasma-optical emission spectroscopy [ICP-OES], PXRD) and in situ synchrotron XAS were used to characterize the structure of the catalyst before, during, and after reaction, and these results compared to catalyst testing conducted in a $1 / 4^{\prime \prime}$ microreactor using both light-off and pseudo-steady-state measurements. The full details of materials preparations, characterization, and testing are provided in the Supporting Information.

\section{DFT METHODS}

Calculations were carried out using the VASP 5.4 program and full details are given in the Supporting Information. Briefly, a $\mathrm{Ni}(100)$ surface was modeled by a $(3 \times 3 \times 5)$ supercell containing 45 atoms and a $15 \AA$ vacuum space between the slab surfaces. This was large enough to accommodate reactants and products and to examine different $\mathrm{Au} / \mathrm{Ni}$ compositions. A larger $(6 \times 3 \times 5)$ supercell model was used to introduce surface steps in order to simulate the behavior of nanoparticles embodying low-coordination sites. In the geometry optimizations, all layers of the slab were allowed to relax and possible changes in cell parameters at the highest $\mathrm{Au}$ content were found to be negligible. Transition state calculations were done using the climbing image version of a nudged elastic band algorithm. Note, the entropic contribution of dinitrogen gas $(\sim 0.65 \mathrm{eV})$ is omitted from energy landscapes, as it contributes a constant shift to the $0 \mathrm{eV}$ reference and is therefore not significant in the calculation of energy barriers.

\section{RESULTS AND DISCUSSION}

A series of five catalysts with different $\mathrm{Au}: \mathrm{Ni}$ ratios were prepared from colloidal nanoparticles, as described earlier. ${ }^{11,12}$ Electron micrographs and size distributions of the nanoparticles before deposition onto the alumina catalyst support are shown in the Supporting Information and are summarized in Table 1. Table 1 (top, columns 2 and 3 ) additionally shows the $\mathrm{Au}: \mathrm{Ni}$ ratio obtained by ICP analysis for each composition and the $\mathrm{Au}: \mathrm{Ni}$ area ratios for single particles measured by EDS, which follow the same general trend, thus confirming the presence of both $\mathrm{Au}$ and $\mathrm{Ni}$ in individual nanoparticles (further details, including exemplar images showing the EDS measurements of separate particles, are given in the Supporting Information).

The catalysts were prepared from the colloidal nanoparticles by deposition onto the support, calcination and reduction. After nanoparticle deposition onto the support, temperature programmed oxidation (TPO, Supporting Information) showed that very substantial quantities of organic residue remained, arising from the nanoparticle synthesis method, despite extensive washing, as described in the experimental section in the Supporting Information. This was evidenced by an $\sim 20 \%$ mass loss during the TPO measurements and the coincidence in temperature between the maximum in the 
differential weight of the sample, and the production of both $\mathrm{CO}_{2}$ and $\mathrm{H}_{2} \mathrm{O}$ confirms that this weight loss is due to oxidation of hydrocarbon material. The need to remove residual polymer capping materials is an important and often overlooked point when catalysts are derived from colloidal nanoparticles, especially in view of the strikingly high ratio $(>10: 1)$ between the mass of hydrocarbon and the mass of actual metal present in these samples. Omission of this step could compromise both the validity of results and their interpretation. Because the TPO traces exhibited a high temperature shoulder extending to ca. $500{ }^{\circ} \mathrm{C}$, all catalysts were calcined at $500{ }^{\circ} \mathrm{C}$ in an $\mathrm{O}_{2} / \mathrm{He}$ flow for $1 \mathrm{~h}$, to ensure complete removal of the residual hydrocarbon. This is especially important with respect to lightoff measurements where $\mathrm{CO}_{2}$ production and $\mathrm{NO}$ consumption rates were measured with catalysts derived from these nanoparticles. XPS of the calcined catalysts showed only a very small $\mathrm{C} 1 \mathrm{~s}$ signal (see the Supporting Information), corresponding at most to $0.5 \mathrm{wt} \%$ (which likely results from sample handling, as is common in XPS). It is of fundamental importance that after exposure to reaction conditions no carbon was detected by XPS. The removal of capping agent by high temperature oxidative pretreatment was accompanied by a significant increase in particle size from $\sim 3$ to $\sim 10 \mathrm{~nm}$ for the bimetallic samples, as indicated in Table 1 and by the micrographs in Figure 1. These materials were the uncapped, stable precatalysts used in this study. After reduction and subsequent catalytic testing, the particles maintained a stable size (Table 1 and Figure 1). For completeness, estimated sizes based on the fcc $\mathrm{Au}$ (311) reflection at $\sim 78^{\circ} 2 \theta$ in the PXRD patterns of the samples are shown in Table 1. (While the trends in PXRD sizes broadly agree with the numbers obtained from TEM, some caution should be exercised making comparisons as this reflection only accounts for the fcc Aulike crystallite within the nanoparticles, and so may exclude some nickel-rich components, and the comparison is between a number and a volume distribution.) Notably, the pure gold sample exhibits rapid agglomeration during calcination but redisperses again under reaction conditions, a fact attested to by both microscopy (a local technique) and PXRD (a bulk technique). As this only occurs for the pure gold sample, it is not of primary importance to the system at hand. However, it could speculatively be suggested that this behavior in $\mathrm{H}_{2}$ or $\mathrm{CO}$ and $\mathrm{NO}$ is similar to that witnessed in the presence of iodine during methanol carbonylation reactions. ${ }^{16}$

As shown by the EDS elemental composition ratios in Table 1 , the bimetallic nanoparticles did indeed contain both $\mathrm{Au}$ and $\mathrm{Ni}$; the spatial distribution of the metals and their oxidation states are considered below. The substantial changes in particle size that occurred as a result of preprocessing the nanoparticles to form the active catalysts (Table 1) underline the importance of cradle-to-grave characterization of nanoparticle catalysts, in contrast to the common practice of focusing attention on nascent materials as opposed to those that are actually used for and emerge from catalytic experiments.

Ex situ XPS and PXRD measurements were made at different stages of the catalysts' fabrication and evolution (from nanoparticle precatalysts to the calcined, reduced and used forms). Figure 2 shows XP spectra obtained after calcination: a gradual shift in the $\mathrm{Ni} 2 \mathrm{p}_{3 / 2}$ signal to higher binding energies was apparent as the Au content was increased (full spectra shown in the Supporting Information). This is consistent with electron transfer from $\mathrm{Ni}$ to $\mathrm{Au}$ and in keeping with their Pauling electronegativities of 1.91 and 2.54, respectively.

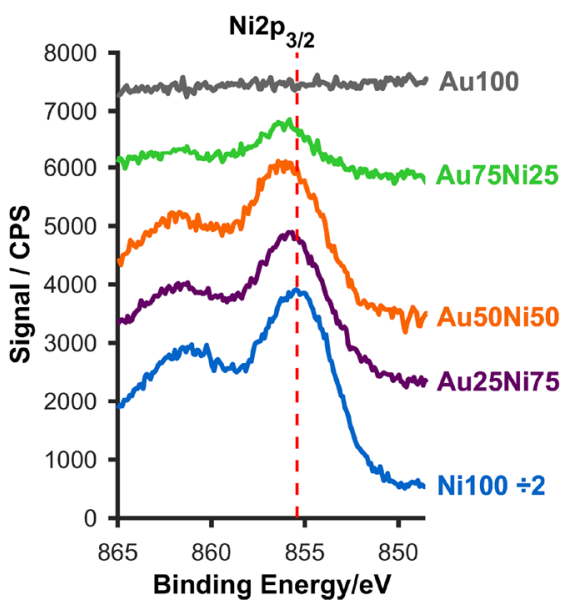

Figure 2. $\mathrm{Ni} 2 \mathrm{p} \mathrm{XP}$ spectra expanded in the region of $\mathrm{Ni} 2 \mathrm{p}_{3 / 2}$ as a function of elemental composition of the five $\alpha-\mathrm{Al}_{2} \mathrm{O}_{3}$ supported samples after calcination, the nominal molar \% composition is shown in the figure legend. The vertical dashed line is a guide to the eye, and it highlights the gradual shift to higher binding energies as the gold content in the sample increases. The spectra are calibrated to the $\mathrm{Al}$ $2 \mathrm{p}$ emission, which has a value of $74.0 \mathrm{eV}$ for $\mathrm{Al}$ in the $\mathrm{Al}_{2} \mathrm{O}_{3}$ support. Signal intensities are as acquired and not normalized.

Smaller shifts were visible in the $\mathrm{Au} 4 \mathrm{f}$ and $4 \mathrm{~d}$ spectra (Supporting Information), with the effect possibly being diminished due to the larger number of electrons involved. Attribution of the changes in $\mathrm{Ni} 2 \mathrm{p}$ binding energy to a core level shift is supported by the same trend being observed for the $\mathrm{Ni} \operatorname{LMM}(3 \mathrm{p} \rightarrow 2 \mathrm{p})$ Auger electron kinetic energies (Supporting Information). For the pure $\mathrm{Ni}$ catalyst and the $\mathrm{Au}_{50} \mathrm{Ni}_{50}$ catalyst, XP spectra were also acquired after (i) reduction and (ii) catalysis using a high pressure cell attached to the XP spectrometer (see experimental details in the Supporting Information). This eliminated artifacts that would result from air handling of the sample. An increase of $\sim 0.7 \mathrm{eV}$ in the $\mathrm{Ni} 2 \mathrm{p}_{3 / 2}$ binding energy of the bimetallic $\mathrm{Au}_{50} \mathrm{Ni}_{50}$ catalyst relative to the pure $\mathrm{Ni}$ catalyst was consistently observed for both reduced and oxidized samples. This implies that $\mathrm{Au}$ withdraws electrons from $\mathrm{Ni}$, thus inhibiting its oxidation. Nevertheless, for both pure $\mathrm{Ni}$ and the bimetallic $\mathrm{Au}_{50} \mathrm{Ni}_{50}$ catalyst the $\mathrm{Ni} 2 \mathrm{p}_{3 / 2}$ binding energy of the postcatalysis sample was much closer to that of the oxidized form than the reduced form of the catalyst, indicating substantial Ni oxidation in this material. More direct light is shed on this important issue by the XAS results obtained under actual working conditions (in situ), as discussed below (and seen in Figures 6 and 7).

While XPS substantiates the occurrence of $\mathrm{Ni} \rightarrow \mathrm{Au}$ electronic transfer, it provides no indication of the range of this effect, nor of the nanoparticle structure. PXRD was therefore used to investigate the possibility of alloy formation within nanoparticles. The PXRD patterns (Supporting Information) were dominated by features attributable to the $\alpha-\mathrm{Al}_{2} \mathrm{O}_{3}$ support, but a number of reflections attributable to fcc $\mathrm{Au}$ were apparent. As expected, no $\mathrm{Ni}$ or $\mathrm{NiO}$ reflections were visible against the $\mathrm{Al}_{2} \mathrm{O}_{3}$ background, due to the much smaller atomic number of $\mathrm{Ni}$ versus $\mathrm{Au}$. Given the different atomic radii of the two metals, alloy structures should show substantial shifts in $2 \theta$ positions for the metallic reflections (Vegard's law). Figure 3 summarizes the PXRD data for the different samples before and after calcination, and also after catalytic testing; also 


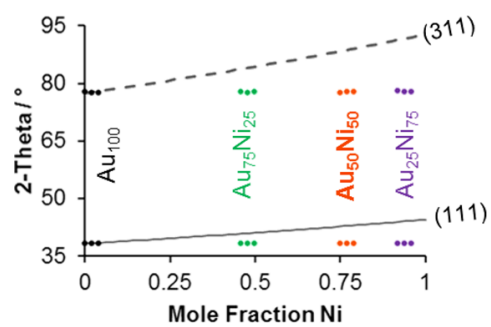

Figure 3. The $2 \theta$ positions of the (111) and (311) Bragg reflections for the four gold-containing samples: each cluster of three dots denotes the supported sample before calcination, the calcined sample and the postcatalysis sample (left $\rightarrow$ right) for the compositions shown. Calculated Vegard's law $2 \theta$ positions for the (111) and (311) reflections are shown by the gray solid line and gray dotted line, respectively (the clusters of dots would be expected to fall on this line if fcc alloys of the composition shown were present).

shown are the expected position of the reflections for each composition. Clearly, at every stage, the samples showed no evidence of significant alloy crystal phases when examined ex situ: only a very small incorporation of $\mathrm{Ni}$ into $\mathrm{Au}$ was evident in line with the relative concentrations in each sample. However, as we shall see, XAS measurements carried out under in situ conditions unambiguously demonstrated that extensive alloy formation occurred at $550{ }^{\circ} \mathrm{C}$ in reaction gas, and that it was reversible with temperature. Clearly, reliance on ex situ characterization techniques can be seriously misleading in the interpretation of catalytic data.

The five catalysts (based on two pure metal and three bimetallic samples) were tested for activity in the $\mathrm{CO}+\mathrm{NO}$ reaction by means of light-off measurements, followed by steady state measurements recorded after stable performance was reached at $550{ }^{\circ} \mathrm{C}$. The latter procedure was important in confirming catalyst stability and the establishment of a steady state, i.e., the observed reactivity was truly catalytic and did not result from reaction of $\mathrm{NO}$ with residual synthetic reagents (e.g., polymer capping agent). Note that this protocol was not followed in previous studies of this system. ${ }^{12,13,17}$ Table 2 summarizes the resulting steady state reaction data. All catalysts exhibited low $\mathrm{N}_{2} \mathrm{O}$ formation at $550{ }^{\circ} \mathrm{C}$, a temperature that falls within the typical operating window for such catalysts; ${ }^{18}$ very conspicuously, the $\mathrm{Au}_{25} \mathrm{Ni}_{75}$ and $\mathrm{Au}_{50} \mathrm{Ni}_{50}$ compositions delivered much higher NO conversions

Table 2. Steady State Conversion and Selectivity for Five Catalysts Tested under a NO-CO Feed ${ }^{a}$

\begin{tabular}{cccc}
\multicolumn{1}{c}{ catalyst } & $\begin{array}{c}\% \mathrm{NO} \\
\text { conversion }\end{array}$ & $\begin{array}{c}\% \mathrm{CO} \\
\text { conversion }\end{array}$ & $\begin{array}{c}\% \mathrm{~N}_{2} \mathrm{O} \\
\text { selectivity }\end{array}$ \\
$\mathrm{Ni}_{100} / \alpha-\mathrm{Al}_{2} \mathrm{O}_{3}$ & 25 & 25 & 0.1 \\
$\mathrm{Au}_{25} \mathrm{Ni}_{75} / \alpha-\mathrm{Al}_{2} \mathrm{O}_{3}$ & 100 & 98 & 0.0 \\
$\mathrm{Au}_{50} \mathrm{Ni}_{50} / \alpha-\mathrm{Al}_{2} \mathrm{O}_{3}$ & 100 & 100 & 0.0 \\
$\mathrm{Au}_{75} \mathrm{Ni}_{25} / \alpha-\mathrm{Al}_{2} \mathrm{O}_{3}$ & 20 & 19 & 0.8 \\
$\mathrm{Au}_{100} / \alpha-\mathrm{Al}_{2} \mathrm{O}_{3}$ & 6 & 6 & 0.3
\end{tabular}

${ }^{a} 1000 \mathrm{ppm}$ of NO, $1000 \mathrm{ppm}$ of CO, He balance. Each catalyst was generated by pretreating immobilized nanoparticle samples by oxidation in synthetic air $\left(\mathrm{O}_{2} 21 \%\right.$, He balance) at $300{ }^{\circ} \mathrm{C}$ (heating rate $=10^{\circ} \mathrm{C} \mathrm{min}^{-1}$, hold time $=1 \mathrm{~h}$ ) before cooling and switching gas feed to $5 \% \mathrm{H}_{2}$, He balance for reduction. Reduction was conducted in situ by heating at $10{ }^{\circ} \mathrm{C} \mathrm{min}^{-1}$ to $550{ }^{\circ} \mathrm{C}$ for $1 \mathrm{~h}$ and cooling under $5 \% \mathrm{H}_{2}$ in $\mathrm{He}$ before admitting the reactive gases. The amount of 60 $\mathrm{mg}$ of sample was loaded into the reactor in each case. Total gas flow rate $=100 \mathrm{sccm}, \mathrm{GSV}=1.6 \mathrm{~L} \mathrm{~min}^{-1} \mathrm{gcat}^{-1}$. than the others. The similar $\mathrm{CO}$ and $\mathrm{NO}$ conversions (Supporting Information) confirm that it was indeed the intended reaction that was being studied, unperturbed by artifacts due to consumption of residual synthetic agents initially present on the nanoparticles. Light-off profiles are shown in more detail in Figure 4, which reveals some important points. The

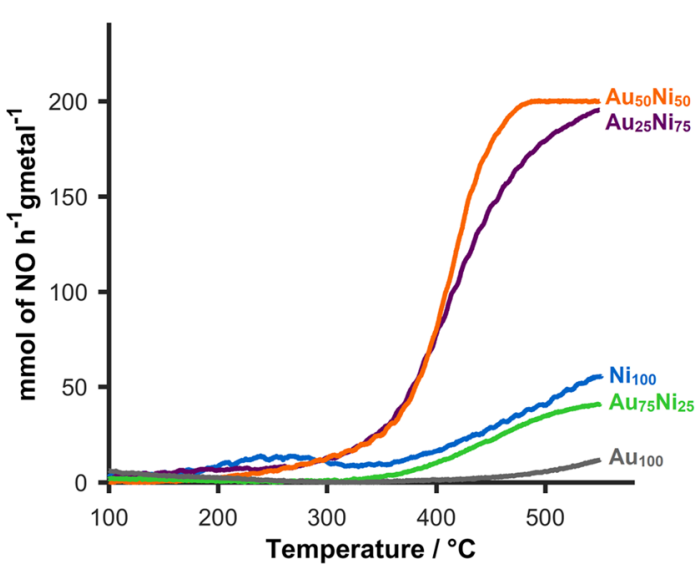

Figure 4. Light-off data for the five catalysts tested under a $\mathrm{NO}-\mathrm{CO}$ feed: $1000 \mathrm{ppm}$ of NO, $1000 \mathrm{ppm}$ of CO, He balance being ramped from 100 to $550{ }^{\circ} \mathrm{C}$, showing the activity normalized to total metal content by mass $(\mathrm{Au}+\mathrm{Ni})$. Each catalyst was generated by pretreating immobilized nanoparticle samples by oxidation in synthetic air $\left(\mathrm{O}_{2} 21 \%\right.$, He balance) at $300{ }^{\circ} \mathrm{C}$ (heating rate $=10$ ${ }^{\circ} \mathrm{C} \min ^{-1}$, hold time $=1 \mathrm{~h}$ ) before cooling and switching gas feed to $5 \% \mathrm{H}_{2}, \mathrm{He}$ balance for reduction. Reduction was conducted in situ by heating at $10{ }^{\circ} \mathrm{C} \mathrm{min}^{-1}$ to $550{ }^{\circ} \mathrm{C}$ for $1 \mathrm{~h}$ and cooling under $5 \% \mathrm{H}_{2}$ in He before admitting the reactive gases. The amount of $60 \mathrm{mg}$ of sample was loaded into the reactor in each case. Total gas flow rate = $100 \mathrm{sccm}, \mathrm{GSV}=1.6 \mathrm{~L} \mathrm{~min}^{-1} \mathrm{~g}_{\mathrm{cat}}{ }^{-1}$.

profiles refer to NO consumption, but, as shown by the full profiles for each catalytic reaction (Supporting Information), the overall process was highly selective and essentially stoichiometric with respect to $\mathrm{CO} / \mathrm{NO}$ (small quantities of $\mathrm{N}_{2} \mathrm{O}$ were produced only at low temperature). Initially, all catalysts were fully reduced. The $\mathrm{Ni}$ catalyst showed pronounced low temperature activity, quickly deactivated, and only slowly regained activity with subsequently increasing temperature. Pure gold was almost inactive throughout. $\mathrm{Au}_{75} \mathrm{Ni}_{25}$ was slightly less active than pure nickel, but it did not display the low temperature activity shown by pure $\mathrm{Ni}$. The two most active catalyst compositions $\left(\mathrm{Au}_{25} \mathrm{Ni}_{75}\right.$ and $\mathrm{Au}_{50} \mathrm{Ni}_{50}$ ) lit-off at a similar temperature and exhibited similar kinetics, with a steep rise in activity at $\sim 400{ }^{\circ} \mathrm{C}$. With increasing temperature, despite similar masses, loadings, and reactor geometry (i.e., the same mass transfer characteristics), the $\mathrm{Au}_{50} \mathrm{Ni}_{50}$ composition was more active at the highest temperatures, reaching saturation before $\mathrm{Au}_{25} \mathrm{Ni}_{75}$. These trends are explained well by the in situ XAS experiments described below (and seen in Figures 6 and 7).

It has been proposed that the beneficial effect of $\mathrm{Au}$ in enhancing the activity of $\mathrm{Au} / \mathrm{Ni}$ catalysts for the $\mathrm{CO}+\mathrm{NO}$ reaction was due to inhibition of $\mathrm{Ni}$ oxidation, a conclusion based on experiments with a $\mathrm{Au}_{50} \mathrm{Ni}_{50}$ nanoparticle system similar to that used here. ${ }^{13,17}$ Subsequently, based on single crystal model studies, ${ }^{12}$ the same group proposed a different explanation; namely, that $\mathrm{Au} / \mathrm{Ni}$ electronic interaction decreased the activation barrier to $\mathrm{N}+\mathrm{N}$ recombination, thought to be the rate limiting step. ${ }^{12}$ Fundamental under- 


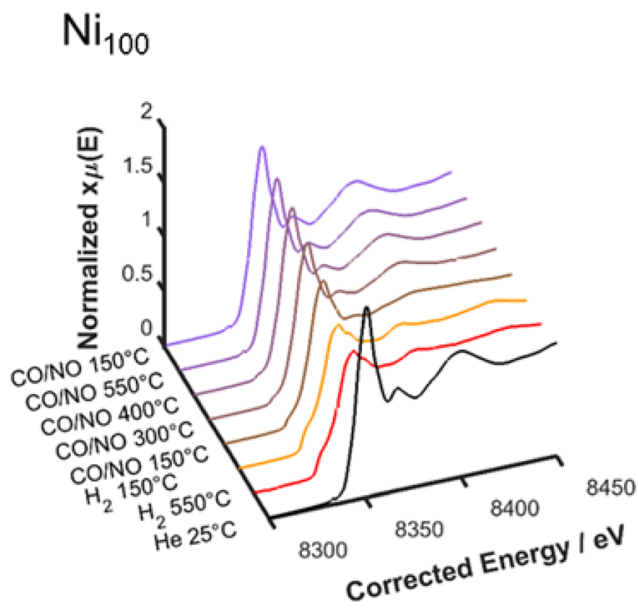

\section{$\mathrm{Au}_{25} \mathrm{Ni}_{75}$}
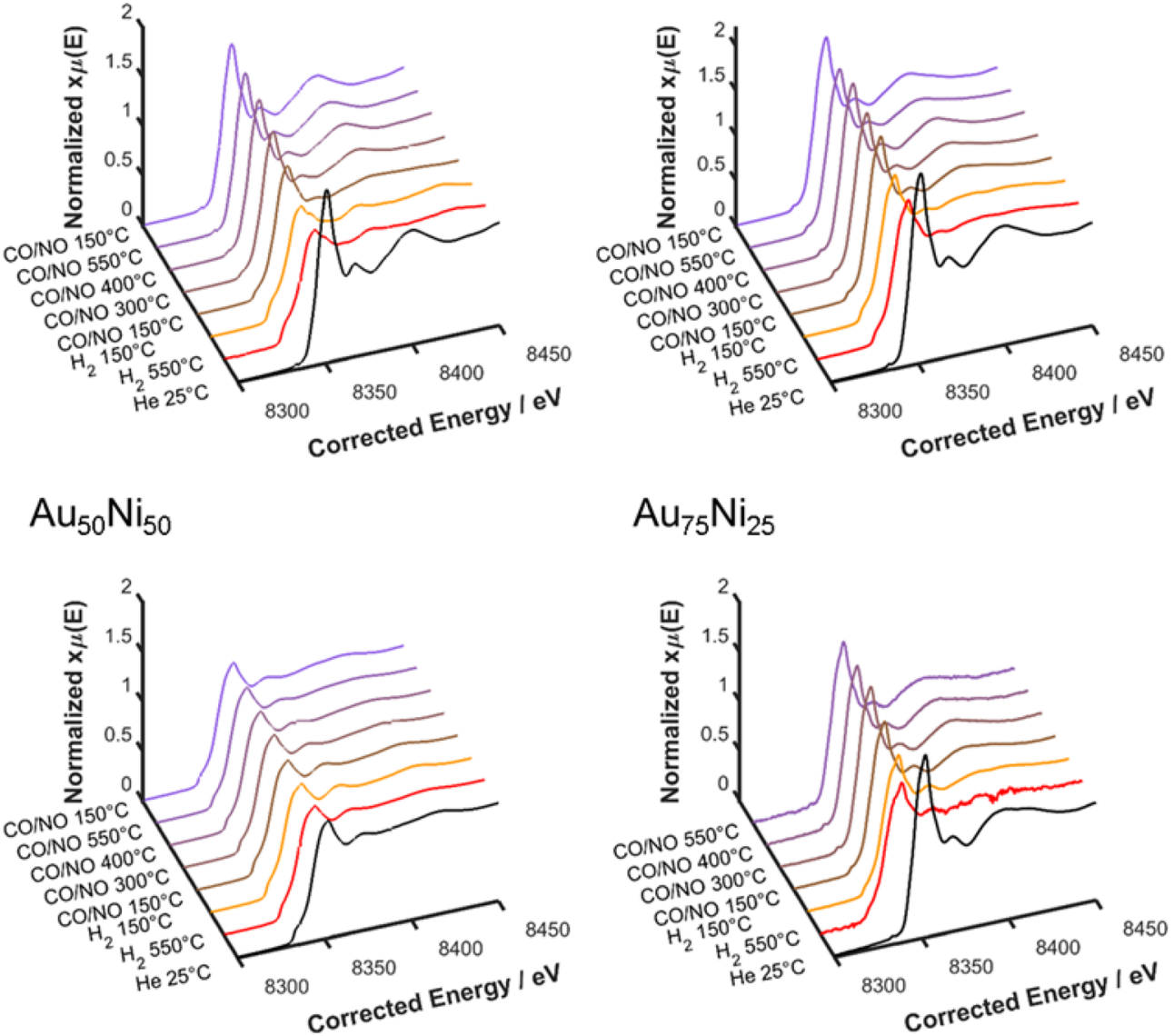

Figure 5. In situ Ni K-edge XANES spectra of the four Ni-containing samples as a function of gas conditions and indicated temperatures. Energy scale corrected to $\mathrm{Ni}$ foil edge at $8333 \mathrm{eV}$.

standing of the origin and mechanism of activity promotion by $\mathrm{Au}$ in this important reaction is essential for rational catalyst development. Theoretical calculations described below establish, among other things, that reduced $\mathrm{Ni}$ sites are required and that the $\mathrm{Ni} \rightarrow \mathrm{Au}$ electronic interaction does indeed promote $\mathrm{N}+\mathrm{N}$ recombination. The significance of both factors will be discussed. Importantly, in situ XAS measurements enabled conclusions to be drawn about both the $\mathrm{Ni}$ oxidation state, which does not correlate with activity, and the frequency of $\mathrm{Au}-\mathrm{Ni}$ interactions present under reaction conditions.

$\mathrm{X}$-ray absorption near edge structure (XANES) spectroscopy was used to probe the $\mathrm{Ni}$ oxidation state in the samples following calcination, reduction and after being used as catalysts. Figure 5 shows the Ni K-edge XANES region for all the Ni-containing samples, which were loaded into the XAS cell in their calcined form (measured in $\mathrm{He}$ at $25^{\circ} \mathrm{C}$, black spectrum), reduced at $550{ }^{\circ} \mathrm{C}$ in $\mathrm{H}_{2}$, cooled and then exposed to a $\mathrm{CO}+\mathrm{NO}$ feed; spectra were acquired at different temperatures during this sequence, as shown. Typically, three or more spectra were acquired under each set of conditions to confirm establishment of a stable state and then averaged. It is immediately apparent that the so-called white line (peak height at the edge), whose intensity is commonly taken as indicating oxidation state, changed abruptly between calcination (black), where its high intensity signifies extensive $\mathrm{Ni}$ oxidation, and subsequent high temperature reduction in hydrogen (red), where its strong attenuation indicates a mostly reduced form of
Ni. Exposure to reaction conditions resulted in rapid oxidation of the pure $\mathrm{Ni}$ sample while in contrast the $\mathrm{Au}_{50} \mathrm{Ni}_{50}$ sample remained substantially reduced; both $\mathrm{Au}_{25} \mathrm{Ni}_{75}$, which was relatively active, and $\mathrm{Au}_{75} \mathrm{Ni}_{25}$, which was no more active than pure $\mathrm{Ni}$, became significantly oxidized. However, for a number of metals it has been shown that the shift in edge position provides a more reliable gauge of oxidation state. ${ }^{19}$ The observed edge positions under reaction conditions (relative to $\mathrm{Ni}$ foil) for a range of temperatures are illustrated in Figure 6. These indicate that nickel in $\mathrm{Au}_{50} \mathrm{Ni}_{50}$ was the most reduced $(\sim 10.3 \mathrm{eV}$ versus $\mathrm{Ni}$ foil $)$, followed by $\mathrm{Au}_{75} \mathrm{Ni}_{25}$ and $\mathrm{Au}_{25} \mathrm{Ni}_{75}$ $(\sim 11.3$ and $\sim 11.7 \mathrm{eV}$, respectively), and finally pure $\mathrm{Ni}(\sim 12.5$ $\mathrm{eV})$. While this analysis shows that the presence of $\mathrm{Au}$ definitely did contribute to moderating the oxidation state of $\mathrm{Ni}$, there is no significant correlation with the catalytic activity data, where $\mathrm{Au}_{50} \mathrm{Ni}_{50}$ and $\mathrm{Au}_{25} \mathrm{Ni}_{75}$ were both substantially better than the essentially inactive $\mathrm{Au}_{75} \mathrm{Ni}_{25}$ and $\mathrm{Ni}_{100}$ samples.

In situ extended X-ray absorption fine structure (EXAFS) spectroscopy was very revealing, allowing an estimation of the coordination number for different types of metal-metal interactions under reaction conditions. In particular, it enabled distinguishing between $\mathrm{Ni}-\mathrm{Ni}$ and $\mathrm{Ni}-\mathrm{Au}$ (using $\mathrm{Ni}$ K-edge data) and between $\mathrm{Au}-\mathrm{Au}$ and $\mathrm{Au}-\mathrm{Ni}$ (using $\mathrm{Au}$ L-edge data). Fitted data from both edges shows the same general trends in coordination numbers, while $\mathrm{Ni}-\mathrm{O}$ interactions shown by Ni K-edge fits (see the Supporting Information) corroborate the $\mathrm{Ni}$ oxidation state trends seen in the XANES 


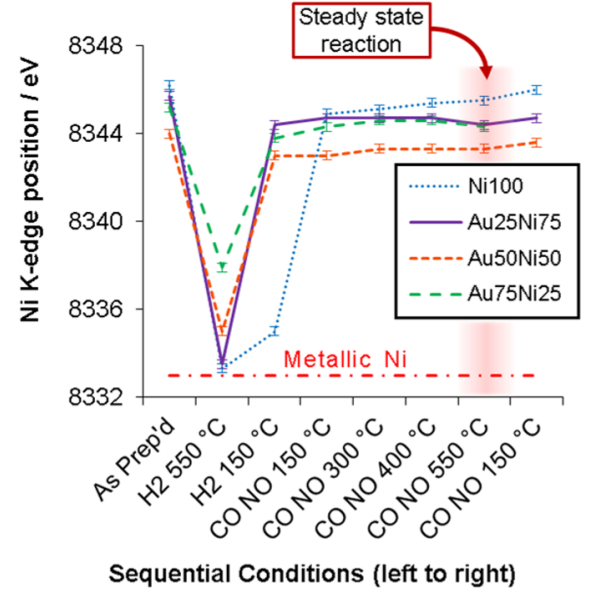

Figure 6. In situ Ni K-edge positions as a function of gas conditions and temperature. Energy scale corrected to $\mathrm{Ni}$ foil edge at $8333 \mathrm{eV}$ whose position is indicated by the dashed red line at the bottom of the graph; even under hydrogen the $\mathrm{Ni}$ was not quite fully reduced. The region corresponding to steady state reaction conditions is highlighted.

data. However, the clearest picture is provided by the coordination numbers derived from the Au L-edge (Figure 7); these were least prone to error, particularly for $\mathrm{Au}_{75} \mathrm{Ni}_{25}$

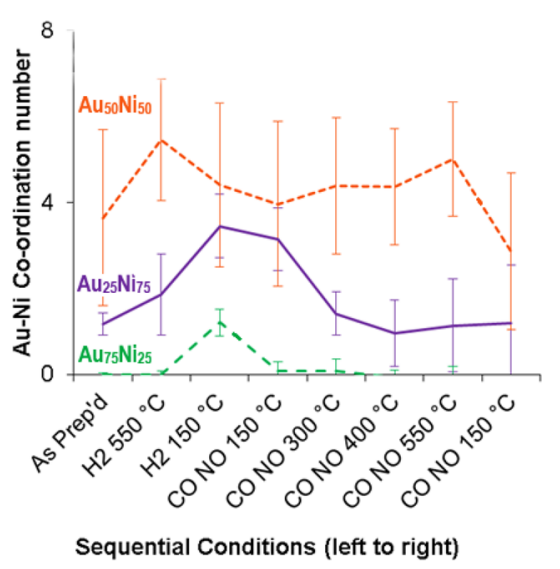

Figure 7. EXAFS derived $\mathrm{Au}-\mathrm{Ni}$ average first nearest neighbor coordination numbers derived from in situ Au L-edge measurements as a function of pretreatment and reaction conditions for the three bimetallic systems studied (full details of the fitting and fitting parameters, and corresponding $\mathrm{Ni} \mathrm{K}$-edge fits are given in the Supporting Information). In a true random alloy of fcc AuNi, each gold atom is expected to have 3,6, or $9 \mathrm{Ni}$ nearest neighbors for the $\mathrm{Au}_{75} \mathrm{Ni}_{25}, \mathrm{Au}_{50} \mathrm{Ni}_{50}$, and $\mathrm{Au}_{25} \mathrm{Ni}_{75}$ compositions, respectively. The error bars shown indicate the uncertainty in coordination number for the specific fit from which the data shown were derived.

data, which could not be fitted reliably at the Ni edge due to the low Ni concentration (Supporting Information). As shown in Figure 7, there is a good correlation between the most reactive catalyst and the $\mathrm{Au}-\mathrm{Ni}$ coordination number. Recall that these measurements are from the perspective of the gold component. Although it may seem surprising that the $\mathrm{Au}_{50} \mathrm{Ni}_{50}$ sample has a higher $\mathrm{Au}-\mathrm{Ni}$ coordination number than the $\mathrm{Au}_{25} \mathrm{Ni}_{75}$ (where there are $50 \%$ more $\mathrm{Ni}$ atoms to potentially interact with when measured from the gold atoms' perspective), this observation accords with the catalytic behavior: the higher the $\mathrm{Au}-\mathrm{Ni}$ coordination number, the better the catalyst.

The initially high activity of $\mathrm{Au}_{25} \mathrm{Ni}_{75}$ may reflect the different time scales of the light-off and spectroscopic measurements. Reduction in hydrogen followed by $\mathrm{CO}+$ $\mathrm{NO}$ at $150{ }^{\circ} \mathrm{C}$ resulted in an increase in $\mathrm{Au}-\mathrm{Ni}$ coordination number followed by a decrease at higher temperatures. During XAS measurements, each set of conditions required $\sim 15 \mathrm{~min}$ acquisition time and $\sim 15$ min for changing temperature and stabilizing the sample. This corresponds to an elapsed time of $\sim 2 \mathrm{~h}$ in going from hydrogen to $\mathrm{CO}+\mathrm{NO}$ at $400{ }^{\circ} \mathrm{C}$, where reactivity differences between $A_{4}{ }_{50} \mathrm{Ni}_{50}$ and the $\mathrm{Au}_{25} \mathrm{Ni}_{75}$ samples were apparent. In contrast, light-off measurement taken at $5{ }^{\circ} \mathrm{C} \mathrm{min}^{-1}$ required only $50 \mathrm{~min}$. It therefore seems very likely that the higher activities in the low temperature region of the light-off for the $\mathrm{Au}_{25} \mathrm{Ni}_{75}$ catalyst, comparable to that of $\mathrm{Au}_{50} \mathrm{Ni}_{50}$, reflected an initially higher $\mathrm{Au}-\mathrm{Ni}$ interaction frequency similar to that of $\mathrm{Au}_{50} \mathrm{Ni}_{50}$ at low temperature. Subsequently, at higher temperatures and in $\mathrm{CO}+\mathrm{NO}$, reactivity decreased due to partial $\mathrm{Au} / \mathrm{Ni}$ segregation.

A final important observation was the clear decrease in $\mathrm{Au}-$ $\mathrm{Ni}$ coordination that occurred when cooling the $\mathrm{Au}_{50} \mathrm{Ni}_{50}$ sample after use as a catalyst under reaction gases; by the time this sample had cooled to $150{ }^{\circ} \mathrm{C}$, the $\mathrm{Au}-\mathrm{Ni}$ coordination number had already decreased very substantially. Indeed, the temperature-dependent increases and decreases in $\mathrm{Au} / \mathrm{Ni}$ intermixing evident in Figure 7 underline the importance of in situ measurements in the acquisition of catalytically relevant information. They also explain why evidence of increased mixing was not seen in the ex situ PXRD and XPS measurements described above, which were recorded after cooling and removal of the reactive gases.

The crucial role of temperature and particle size in determining when intermixing of $\mathrm{Au}$ and $\mathrm{Ni}$ occurs is nicely illustrated by the work by Sopoušek et al., who showed how the phase diagram for miscibility of these metals changes in going from the bulk to nanometric length scales. ${ }^{20}$ For $13 \mathrm{~nm}$ particles, they calculated the depression in temperature for formation of a mixed $(\mathrm{Au}+\mathrm{Ni})$ fcc single phase versus segregation into the separate metals. Figure 8 shows their results, which are directly relevant to an understanding of our work. Also indicated in the figure are the compositions of our nanoparticles and the reaction temperatures that we used.

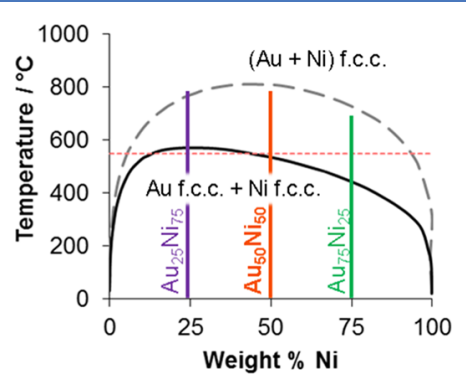

Figure 8. Phase diagram for $\mathrm{Au}-\mathrm{Ni}$ alloying versus separate fcc phases as a function of composition (data taken from ref 17). The gray dashed line is the thermodynamic phase boundary in the bulk, and the solid black line is for a $13 \mathrm{~nm}$ nanoparticle. The horizontal dashed red line highlights the steady state reaction temperature of 550 ${ }^{\circ} \mathrm{C}$, and the vertical lines indicate the bimetallic compositions used in this study (their nominal compositions are indicated, and the actual weight percent plotted is based on the ICP measured composition of the supported nanoparticles). 
(a)

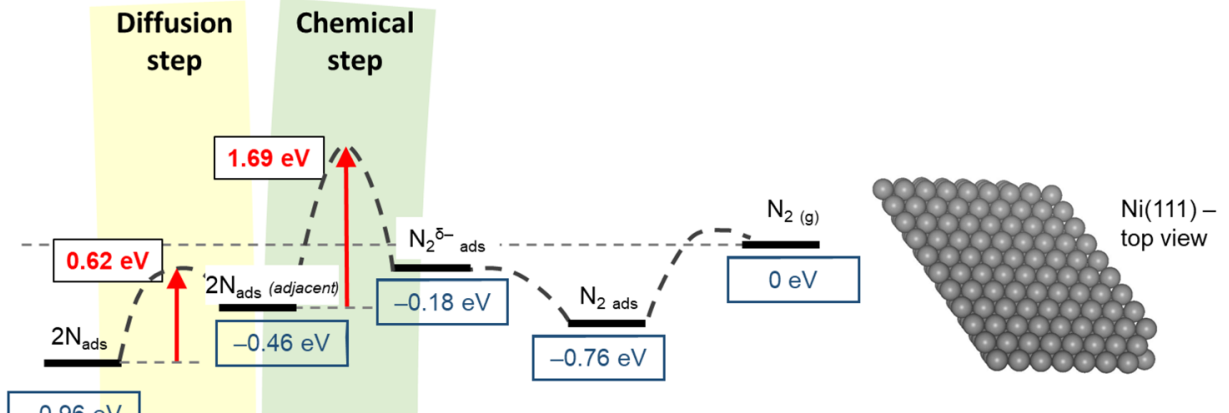

(b)

(c)
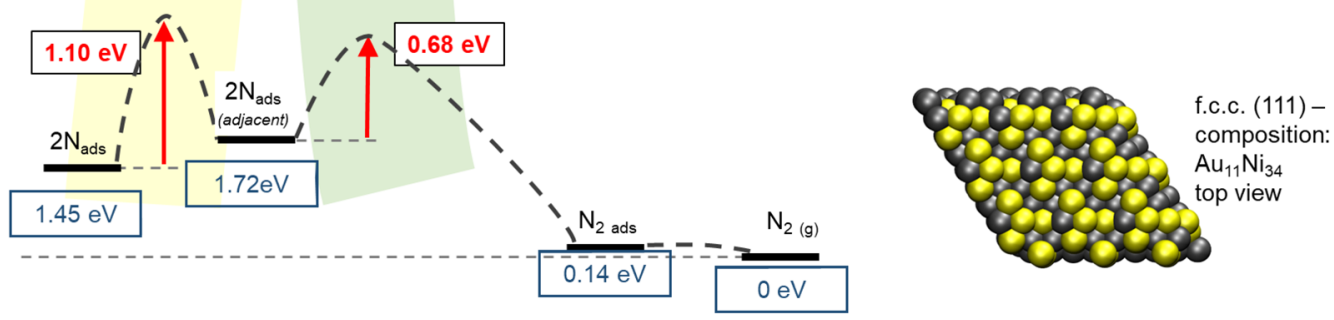

Figure 9. DFT computed energy profiles for the $\mathrm{N}+\mathrm{N}$ recombination reaction on (a) flat $\mathrm{Ni}(111)$ surface model, (b) monatomic step on pure $\mathrm{Ni}(111)$ with inset showing $\mathrm{NO}$ dissociation for comparison, and (c) $\mathrm{Au}_{11} \mathrm{Ni}_{34}$ flat surface model. Barriers for the diffusion steps and chemical steps are shown in red. In all cases, the $0 \mathrm{eV}$ reference is taken to be the $\mathrm{N}_{2}(\mathrm{~g})+$ surface system. The model surfaces employed are shown on the righthand side of the figure.

Figure 8 provides a clear indication that at $550{ }^{\circ} \mathrm{C}$ extensive intermixing of $\mathrm{Au}$ and $\mathrm{Ni}$ can be expected in all cases, and that cooling below that temperature should lead to major changes in nanoparticle constitution, in accord with our catalytic results. The coordination numbers actually identified by EXAFS are of course smaller (on average) than a true alloy (highest are 3-5), but this still points conclusively to the fact that in the working material at temperature the intermixing to gold nickel is occurring. Of course, the presence of reactive gases could alter the picture ${ }^{21}$ to some degree, but the essential message remains: in situ characterization of bimetallic catalysts under operating conditions is an essential prerequisite for acquisition of meaningful data that enable reliable interpretation of catalytic measurements.

DFT Results. In the case of $\mathrm{Rh}$ catalysts, $\mathrm{CO}+\mathrm{NO}$ reaction has been studied many times and it is universally accepted that NO dissociation is the reaction-initiating step, although there is no consensus in regard to other catalytic systems, including those studied here. Another key process, namely, $\mathrm{N}+\mathrm{N}$ recombination has been proposed as the overall rate-limiting process. ${ }^{5}$ As we shall demonstrate in this section, for Ni-based catalysts, detailed calculations provide clear confirmation that
NO dissociation is not rate-controlling, whereas the associative $\mathrm{N}+\mathrm{N}$ reaction is rate-controlling. We also show how addition of $\mathrm{Au}$ to $\mathrm{Ni}$ switches the rate-limiting process for $\mathrm{N}+\mathrm{N}$ recombination from the association of adjacent $\mathrm{N}$ atoms to the surface diffusion of $\mathrm{N}$. The energetics of both processes have been examined in detail, with particular reference to (i) the effects of adding $\mathrm{Au}$ to $\mathrm{Ni}$ and (ii) the effect of surface steps. Examination of the latter aspect is relevant to rationalization of nanoparticle behavior where surface properties may differ significantly from those of extended facet planes due to the presence of steps, edges, and other low coordination sites. In addition, given the experimental results, which showed substantial oxidation of $\mathrm{Ni}$ in certain circumstances, we investigated whether $\mathrm{NiO}$ could contribute to the observed catalytic behavior. All calculations were based on (111)oriented slabs of $\mathrm{Ni}$, modified by introduction of $\mathrm{Au}$ atoms (see the Supporting Information for details), step sites, or both as (111) planes are expected to dominate the surfaces of relatively large particles such as ours. All calculations were based on (111)-oriented slabs of $\mathrm{Ni}$, modified by introduction of $\mathrm{Au}$ atoms, step sites, or both. (In the interest of brevity, we 
shall refer to the $\mathrm{N}+\mathrm{N}$ associative reaction as "recombination”, even though this designation is not strictly accurate.)

$\mathrm{NO}$ Dissociation on $\mathrm{Ni}$ and $\mathrm{Au} / \mathrm{Ni}$. NO adsorption and dissociation on smooth pure $\mathrm{Ni}(111)$ is exothermic by $3.5 \mathrm{eV}$ with an activation barrier of $1.38 \mathrm{eV}$. This is in good agreement with earlier work $(1.31 \mathrm{eV}) .^{22}$ The effect of introducing $\mathrm{Au}$ atoms was investigated by examining three different initial adsorption sites and eight different final configurations for the resulting $\mathrm{O}$ and $\mathrm{N}$ adatoms. The most favorable pathway corresponded to a somewhat reduced exothermicity $(\sim 1 \mathrm{eV})$, while the activation barrier remained essentially unchanged and too high to account for the experimentally observed facile dissociation of $\mathrm{NO}$ on $\mathrm{Ni}$ on both single crystals ${ }^{23,24}$ and supported catalysts ${ }^{25}$ at around room temperature. We therefore examined NO on a stepped Ni (111) surface. This was found to strongly adsorb NO and greatly reduce the barrier for dissociation to $0.24 \mathrm{eV}$. Given the much higher activation barriers found for various modes of the $\mathrm{N}+\mathrm{N} \rightarrow \mathrm{N}_{2}$ reaction (smooth $\mathrm{Ni}$ surface, steps, addition of $\mathrm{Au}$, see below), we may conclude that the latter reaction, and not NO dissociation, was always rate-limiting.

NO Dissociation on NiO. As noted above, our experimental results showed that oxidized $\mathrm{Ni}$ was present under certain reaction conditions. We therefore tested the possibility that the reaction initiating step, NO dissociation, could occur on $\mathrm{NiO}$. The $(100) \mathrm{NiO}$ surface was represented by a $(4 \times 4 \times 4)$ supercell that took account of the magnetic properties of $\mathrm{NiO}$, with $\mathrm{Ni}$ atoms ordered in alternate high and low spin layers along the [111] direction. The adsorption geometry of $\mathrm{NO}$ was vertically atop a $\mathrm{Ni}$ atom with the $\mathrm{N}$ atom above the surface. All other NO geometries did not produce a bound state. Four different geometries for the $\mathrm{N}+\mathrm{O}$ products were tested, the most stable corresponding to the $\mathrm{O}$ atom above a surface $\mathrm{Ni}$ with the $\mathrm{N}$ atom in a bridge site between $\mathrm{Ni}$ and $\mathrm{O}$ atoms. This best-case process is highly endothermic (+ $4.3 \mathrm{eV})$, from which we may conclude that $\mathrm{NiO}$ is not a catalytically active phase for the $\mathrm{CO}+\mathrm{NO}$ reaction.

$\mathbf{N}+\mathbf{N} \rightarrow \mathbf{N}_{2}$ "Recombination" Reaction. The flat Ni (111) surface was modeled by a $(3 \times 3)$ slab containing five layers of metal and a vacuum space of $15 \AA$ in the $c$ direction. This generates a supercell of $\sim 7.5 \AA$ in the $a$ and $b$ directions, similar to models used in the literature, and sufficient to obtain converged adsorption energies in systems similar to those studied here. ${ }^{22,26}$ Upon adsorption, $\mathrm{N}$ atoms acquire a substantial negative charge (Bader formal charge $\sim N^{-1}$ ) which gives rise to the $0.62 \mathrm{eV}$ diffusion barrier that must be overcome for two well separated $\mathrm{N}$ atoms to arrive at adjacent sites (Figure 9a). However, subsequent reaction to form a $\mathrm{N}_{2}{ }^{\delta-}$ adsorbed intermediate involves crossing a large $1.69 \mathrm{eV}$ barrier (Figure 9a), and it is this chemical reaction step that becomes the rate-determining step on the pure Ni surface. Desorption of the $\mathrm{N}_{\text {2ads }}$ final state is endothermic by $-0.76 \mathrm{eV}$ (Figure 9a), in accord with direct experimental determination of this quantity, ${ }^{27,28}$ which adds confidence to the quantitative validity of the calculations. Introduction of a monatomic step increases the diffusion barrier to $0.8 \mathrm{eV}$ (Figure 9b), which nevertheless remains smaller than the corresponding chemical barrier (1.06 $\mathrm{eV}$, Figure 9b), so that even at step sites on pure $\mathrm{Ni}$ the chemical reaction remains rate-controlling (Figure 9b).

The effects on the reaction of adding gold to the surface were investigated by stepwise addition of $\mathrm{Au}$ atoms, allowing the system to relax at each stage. Increasing amounts progressively reduced the activation barrier for the chemical reaction, while increasing the diffusion barrier (see Supporting Information). The reduction of the chemical barrier is a consequence of the partial negative charge on $\mathrm{Au}$ atoms that arises from $\mathrm{Ni} \rightarrow$ Au charge transfer (see the Supporting Information). Their repulsive interaction with the initial state consisting of two adjacent $\mathrm{N}^{-}$species destabilizes the latter, resulting in a decreased activation barrier for the subsequent chemical reaction step. Note that, although the $\mathrm{N}_{\mathrm{ads}}$ state is higher in energy than the reference state, the interaction of the $\mathrm{N}$ adatom with the surface is strong (we calculate this this to be $4.7 \mathrm{eV}$ on this surface) so a significant concentration of $\mathrm{N}$ adatoms at the surface resulting from $\mathrm{NO}$ molecule dissociation is to be expected. At a composition of $\mathrm{Au}_{11} \mathrm{Ni}_{34}$, the chemical reaction barrier was very markedly reduced by $\sim 1$ to $0.68 \mathrm{eV}$ (Figure 9c), making it significantly lower than the diffusion barrier of $1.1 \mathrm{eV}$ (Figure 9c). The composition $\mathrm{Au}_{11} \mathrm{Ni}_{34}$ in the bulk corresponds stoichiometrically to the highly active $\mathrm{Au}_{25} \mathrm{Ni}_{75}$ catalyst so the quantity of gold is in the right ball-park. However, it must be cautioned that we cannot know the working surface composition: this stoichiometry and choice of structure was made simply to permit theoretical exploration of the effect of "no gold" vs "gold intermixing" scenarios to enable us to interpret the experimental observations. As a result of the inclusion of gold, the identity of the rate-determining step switches from the chemical reaction step to that of the diffusion of $N$ atoms to occupy adjacent sites, as shown in Figure 9c.

Finally, addition of $\mathrm{Au}$ at step sites increases both the diffusion barrier and the chemical reaction barrier. This can be rationalized through the gold atoms at the step edge being negatively charged, $\mathrm{Au}^{\delta--}$. Since the $\mathrm{N}$ adatoms are also negatively charged, the resulting repulsive interaction disfavors their diffusion from the terrace to these sites, thus inhibiting reaction. For example, at the composition $\mathrm{Au}_{20} \mathrm{Ni}_{61}$, these quantities are 2.08 and $2.17 \mathrm{eV}$, respectively, much more activated than they are at pure $\mathrm{Ni}$ steps $(0.80$ and $1.06 \mathrm{eV}$, respectively), so that bimetallic step sites should be inactive and have no effect on the overall reaction rate.

\section{CONCLUSIONS}

Incorporation of $\mathrm{Au}$ greatly increased the activity of $\mathrm{Ni}$ toward the $\mathrm{CO}+\mathrm{NO}$ reaction due to electronic interaction between the two metals, rather than solely by maintaining the presence of metallic $\mathrm{Ni}$ sites, which are important for inducing the dissociation of NO.

Postreaction XPS showed that, with both pure nickel and bimetallic catalysts, the $\mathrm{Ni}$ underwent substantial oxidation.

In situ EXAFS spectroscopy at reaction temperature and in the presence of reaction gas showed extensive and reversible intermixing of $\mathrm{Ni}$ and $\mathrm{Au}$ in the two most active catalysts, which does not occur at room temperature. This underlines the critical importance of such measurements to the correct interpretation of catalytic performance, compared to more conventional and common methodologies based on ex situ postmortem observations carried out at room temperature.

Although the presence of $\mathrm{Au}$ did moderate nickel oxidation as a result of $\mathrm{Ni} \rightarrow \mathrm{Au}$ charge transfer, the oxidation state of $\mathrm{Ni}$ did not correlate with activity across the range of compositions studied. This is in disagreement with an earlier proposal based on the study of only a single catalyst composition. The 50/50 catalyst was the most active. In situ XAS unambiguously demonstrated that extensive $\mathrm{Au}-\mathrm{Ni}$ alloy formation occurred at $550{ }^{\circ} \mathrm{C}$ in reaction gas, that it was reversible with 
temperature, and that there was a good correlation between the most reactive catalyst and the $\mathrm{Au}-\mathrm{Ni}$ coordination number at reaction temperature.

Oxidative pretreatment to remove hydrocarbonaceous residues inevitably introduced during nanoparticle synthesis is of critical importance to making valid measurements of subsequent performance. This step, which preserved the bimetallic nature of the nanoparticles, albeit at the expense of an increase in particle size, if omitted left large quantities of hydrocarbonaceous residues on the catalysts, thus compromising interpretation of results. XPS using a high-pressure cell that prevented air exposure revealed that the catalyst surfaces were entirely free of carbon after exposure to reaction conditions, confirming the validity of our procedures and results.

The experimental findings are fully consistent and very well aligned with the results of DFT calculations which indicated that (i) $\mathrm{N}+\mathrm{N}$ recombination rather than $\mathrm{NO}$ dissociation is rate-controlling and (ii) addition of gold and consequent electronic interaction reduces the overall barrier for the ratedetermining step from 1.69 to $1.1 \mathrm{eV}$, at the same time switching this key step from chemical reaction to surface diffusion. Theory also shows that $\mathrm{NiO}$, which may be present under reaction conditions, is catalytically inert.

The insights provided by this work should assist the design of lower cost bimetallic catalysts intended for the replacement of materials based on platinum group metals. They also emphasize the importance of correct materials pretreatment procedures and appropriate experimental methodologies required for the reliable acquisition and interpretation of results.

\section{ASSOCIATED CONTENT}

\section{S Supporting Information}

The Supporting Information is available free of charge on the ACS Publications website at DOI: 10.1021/acscatal.8b05154.

Additional experimental details, additional computational methods energies and coordinates, TPO, catalyst testing, EDX spectroscopy, TEM, XPS, PXRD, XAS data, and EXAFS fitting details (PDF)

DFT files (ZIP)

\section{AUTHOR INFORMATION}

\section{Corresponding Authors}

*E-mail: rml1@cam.ac.uk (R.M.L).

*E-mail: simon.beaumont@durham.ac.uk (S.K.B.).

\section{ORCID}

Georgios Kyriakou: 0000-0001-6295-844X

Antonio M. Márquez: 0000-0001-6699-064X

Martin J. Taylor: 0000-0002-8810-8942

Andrew E. H. Wheatley: 0000-0002-2624-6063

Javier Fernández Sanz: 0000-0003-2064-7007

Simon K. Beaumont: 0000-0002-1973-9783

Richard M. Lambert: 0000-0002-5794-8818

\section{Present Address}

${ }^{\nabla}$ M.J.T.: Energy and Environment Institute and School of Engineering and Computer Science, Chemical Engineering, University of Hull, Cottingham Road, Hull, HU6 7RX, UK.

Notes

The authors declare no competing financial interest.

\section{ACKNOWLEDGMENTS}

We thank Adam E. Fraser for assistance with sample preparation. A.M.M. and J.F.S. acknowledge support from the European Union FEDER Program and MINECO under Project CTQ2015-64669-P. J.P.H. acknowledge support from the European Union FEDER Program and MINECO under Project CTQ2014-60524-R and ENE2017-88818-C2-1-R. This work was carried out with the support of the Diamond Light Source (SP9577), and the authors are grateful to Andy Dent, Giannantonio Cibin, and Diego Gianolio for their assistance during the synchrotron experiments. G.K. gratefully acknowledges the RSC for the award of a travel grant.

\section{REFERENCES}

(1) Lambert, R. M.; Comrie, C. M. The Oxidation of CO by NO on $\mathrm{Pt}(111)$ and $\mathrm{Pt}(110)$. Surf. Sci. 1974, 46, 61-80.

(2) Ueda, K.; Yoshida, M.; Isegawa, K.; Shirahata, N.; Amemiya, K.; Mase, K.; Mun, B. S.; Kondoh, H. Operando Observation of NO Reduction by CO on $\operatorname{Ir}(111)$ Surface Using NAP-XPS and Mass Spectrometry: Dominant Reaction Pathway to $\mathrm{N}_{2}$ Formation under Near Realistic Conditions. J. Phys. Chem. C 2017, 121, 1763-1769.

(3) Williams, F. J.; Aldao, C. M.; Palermo, A.; Lambert, R. M. A Monte Carlo Simulation of the NO+CO Reaction on Na-Promoted Platinum. Surf. Sci. 1998, 412-413, 174-183.

(4) Rainer, D. R.; Vesecky, S. M.; Koranne, M.; Oh, W. S.; Goodman, D. W. The CO+NO Reaction over Pd: A Combined Study Using Single-Crystal, Planar-Model-Supported, and High-SurfaceArea $\mathrm{Pd} / \mathrm{Al}_{2} \mathrm{O}_{3}$ Catalysts. J. Catal. 1997, 167, 234-241.

(5) Srinivasan, A.; Depcik, C. Review of Chemical Reactions in the NO Reduction by $\mathrm{CO}$ on Rhodium/Alumina Catalysts. Catal. Rev.: Sci. Eng. 2010, 52, 462-493.

(6) Srinivasan, A.; Depcik, C. Review of Chemical Reactions in the NO Reduction by CO on Platinum/Alumina Catalysts. Surf. Rev. Lett. 2012, 19, 1230001.

(7) Chen, T.; Rodionov, V. O. Controllable Catalysis with Nanoparticles: Bimetallic Alloy Systems and Surface Adsorbates. ACS Catal. 2016, 6, 4025-4033.

(8) Sinfelt, J. H. Supported "Bimetallic Cluster" Catalysts. J. Catal. 1973, 29, 308-315.

(9) Koh, S.; Strasser, P. Electrocatalysis on Bimetallic Surfaces: Modifying Catalytic Reactivity for Oxygen Reduction by Voltammetric Surface Dealloying. J. Am. Chem. Soc. 2007, 129, 1262412625.

(10) Araya, P.; Ferrada, C.; Cortés, J. Activity During Reduction of NO by $\mathrm{CO}$ over Bimetallic Palladium-Rhodium/Silica Catalysts. Catal. Lett. 1995, 35, 175-181.

(11) Osaki, M.; Hirata, H.; Hara, N.; Johnson, B.; Wheatley, A.; Skelton, H.; Lepage, M. $\mathrm{NO}_{\mathrm{x}}$ Purification Catalyst. US Patent US 9079167 B2, July 14, 2015.

(12) Beniya, A.; Ikuta, Y.; Isomura, N.; Hirata, H.; Watanabe, Y. Synergistic Promotion of NO-CO Reaction Cycle by Gold and Nickel Elucidated using a Well-Defined Model Bimetallic Catalyst Surface. ACS Catal. 2017, 7, 1369-1377.

(13) Shirakawa, S.; Osaki, M.; Nagai, Y.; Nishimura, Y. F.; Dohmae, K.; Matsumoto, S.; Hirata, H. XAFS Study on Promoting Effect of Au via $\mathrm{NiO}$ Reduction in Au-Ni Bimetallic Clusters. Catal. Today 2017, 281, 429-436.

(14) Holgado, J. P.; Ternero, F.; Gonzalez-delaCruz, V. M.; Caballero, A. Promotional Effect of the Base Metal on Bimetallic $\mathrm{Au}-\mathrm{Ni} / \mathrm{CeO} 2$ Catalysts Prepared from Core-Shell Nanoparticles. ACS Catal. 2013, 3, 2169-2180.

(15) Silverwood, I. P.; Hamilton, N. G.; Laycock, C. J.; Staniforth, J. Z.; Ormerod, R. M.; Frost, C. D.; Parker, S. F.; Lennon, D. Quantification of surface species present on a nickel/alumina methane reforming catalyst. Phys. Chem. Chem. Phys. 2010, 12, 3102-3107. 
(16) Goguet, A.; Hardacre, C.; Harvey, I.; Narasimharao, K.; Saih, Y.; Sa, J. Increased Dispersion of Supported Gold during Methanol Carbonylation Conditions. J. Am. Chem. Soc. 2009, 131, 6973-6975.

(17) Hirata, H. Recent Research Progress in Automotive Exhaust Gas Purification Catalyst. Catal. Surv. Asia 2014, 18, 128-133.

(18) Chorkendorff, I.; Niemantsverdriet, J. W. Concepts of Modern Catalysis and Kinetics, 2nd ed.; Wiley-VCH: Weinheim, 2007.

(19) Bunker, G. Introduction to XAFS: A Practical Guide to X-ray Absorption Fine Structure Spectroscopy; Cambridge University Press: Cambridge, 2010.

(20) Sopoušek, J.; Kryštofová, A.; Premović, M.; Zobač, O.; Polsterová, S.; Brož, P.; Buršík, J. Au-Ni Nanoparticles: Phase Diagram Prediction, Synthesis, Characterization, and Thermal Stability. CALPHAD: Comput. Coupling Phase Diagrams Thermochem. 2017, 58, 25-33.

(21) Beaumont, S. K.; Alayoglu, S.; Pushkarev, V. V.; Liu, Z.; Kruse, N.; Somorjai, G. A. Exploring Surface Science and Restructuring in Reactive Atmospheres of Colloidally Prepared Bimetallic CuNi and CuCo Nanoparticles on $\mathrm{SiO}_{2}$ in situ using Ambient Pressure X-ray Photoelectron Spectroscopy. Faraday Discuss. 2013, 162, 31-44.

(22) Gajdoš, M.; Hafner, J.; Eichler, A. Ab initio Density-Functional Study of NO Adsorption on Close-Packed Transition and Noble Metal Surfaces: II. Dissociative Adsorption. J. Phys.: Condens. Matter 2006, 18, 41.

(23) Brown, W. A.; King, D. A. NO Chemisorption and Reactions on Metal Surfaces: A New Perspective. J. Phys. Chem. B 2000, 104, 2578-2595.

(24) Price, G. L.; Sexton, B. A.; Baker, B. G. The Chemisorption of Nitric Oxide on (110) Nickel Studied by LEED, AES and Thermal Desorption. Surf. Sci. 1976, 60, 506-526.

(25) Morrow, B. A.; Moran, L. E. The Adsorption of $\mathrm{NO}$ and $\mathrm{NO}_{2}$ on Silica-Supported Nickel. J. Catal. 1980, 62, 294-303.

(26) Zeng, Z.-H.; Da Silva, J. L. F.; Li, W.-X. Theory of Nitride Oxide Adsorption on Transition Metal (111) Surfaces: a FirstPrinciples Investigation. Phys. Chem. Chem. Phys. 2010, 12, 24592470.

(27) King, D. A. Nitrogen Adsorption on Nickel and Palladium Films. Surf. Sci. 1968, 9, 375-395.

(28) Parks, E. K.; Nieman, G. C.; Kerns, K. P.; Riley, S. J. The Thermodynamics of Nitrogen Adsorption on Nickel Clusters: $\mathrm{Ni}_{19}-$ $\mathrm{Ni}_{71}$. J. Chem. Phys. 1998, 108, 3731-3739. 